\title{
Enterovirus D68
}

National Cancer Institute

\section{Source}

National Cancer Institute. Enterovirus D68. NCI Thesaurus. Code C125639.

A species of enterovirus in the family Picornaviridae. EV-D68 can cause respiratory illness with symptoms ranging from runny nose, sneezing, cough, and body and muscle aches to wheezing and difficulty breathing. 